\title{
Treatment of dry age-related macular degeneration with dobesilate
}

\author{
P Cuevas, ${ }^{1}$ L A Outeiriño, ${ }^{2} \mathrm{~J}$ Angulo, ${ }^{1} \mathrm{G}$ Giménez-Gallego ${ }^{3}$ \\ ${ }^{1}$ Departamento de Investigación, IRYCIS, Hospital Universitario Ramón y Cajal, Madrid, Spain; \\ 2Departamento de Oftalmología, Hospital de Día Pío XII, Madrid, Spain; \\ ${ }^{3}$ Departamento de Estructura y Función de Proteínas, Centro de Investigaciones Biológicas, CSIC, Madrid, Spain
}

Correspondence to Professor Pedro Cuevas, pedro.cuevas@hrc.es

\begin{abstract}
Summary
The authors present anatomical and functional evidences of dry age-macular degeneration improvement, after intravitreal treatment with dobesilate. Main outcomes measures were normalisation of retinal structure and function, assessed by optical coherence tomography, fundus-monitored microperimetry, electrophysiology and visual acuity. The effect might be related to the normalisation of the outer retinal architecture.
\end{abstract}

\section{BACKGROUND}

This is a very safe and promising efficient treatment for dry age-related macular degeneration (AMD).

\section{CASE PRESENTATION}

This is a representative case from an institutional trial using dobesilate therapy in early dry AMD. This early stage of AMD may not be evident by ophthalmoscopic examination but can be inferred by reduced retinal function. ${ }^{1}$ Optical coherence tomography (OCT) is unequivocally the method for accurate early morphological detection, in vivo, of outer retinal layer changes in dry AMD. ${ }^{2} 3$

This study was performed with patient's consent after the Ethical Committee approval of our Institution. A 54-year-old man presented with methamorphia in his right eye. A comprehensive ocular examination including Shellen visual acuity measurements and OCT was performed at baseline and 7 and 14 days after dobesilate injection. Fundus-monitored microperimetry was performed at baseline and after 14 days of treatment. The patient received an intravitreal solution of dobesilate $(150 \mu 1)$ under sterile conditions, following the International Guidelines for intravitreal injections ${ }^{4}$ in his right eye. Dobesilate was administered as a $12.5 \%$ solution of diethylammonium 2,5-dihydroxybenzenesulfonate (etamsylate; Dicynone Sanofi-Aventis). The $\mathrm{pH}$ of the solution was 3.2 at the opening of the phial and 5.2 after a 1:20 dilution in Milli-O water, respectively. Mitogenesis experiments carried out as described by Fernández et a ${ }^{5}$ show that etamsylate inhibits FGF-driven mitogenesis with the same efficiency than the potassium dobesilate salt employed in those studies which first demonstrated this inhibitory activity (not shown).

As depicted in the OCT image before treatment (figure 1A), the patient had both foveal and temporal extrafoveal photoreceptor disruption. At baseline, inner retinal layers were normal, whereas the outer retinal layers showed structural alterations: 1) the integrity of photoreceptor inner segment and outer segment was not preserved (layers corresponding to those labelled 1 and 2 at the inset); 2) retinal pigment epithelium (RPE) showed rarefactions and thinning (layer labelled 3 at the red framed inset). In contrast, as figure $1 B, C$ show, normalisation of outer retinal layers was achieved after dobesilate treatment. In addition, central foveal thickness increased after dobesilate treatment $(138 \mu \mathrm{m}$ at baseline vs $200 \mu \mathrm{m}$ after 7 days of treatment ). Retinal sensitivity map assessed by fundus-monitored microperimetry normalised after 14 days of treatment (figure 2A,B). The normalisation of retinal structure was associated with a gain of visual acuity: 0.4 at baseline versus 0.8 and 0.9 after 7 and 14 days of treatment, respectively. As an additional functional assessment, a full field electroretinogram (ERG) of the treated right eye of the patient was performed after 1 month of treatment, according to standard protocols recommended by the International Society for Clinical Electrophysiology of Vision, and compared with the record of the normal untreated left eye. As figure 3 shows, ERG patterns were similar in untreated and treated eye, suggesting no photoreceptor toxicity of intravitreal dobesilate.

\section{DISCUSSION}

Age-related macular degeneration (AMD) is estimated to affect between 30 and 50 million people worldwide, ${ }^{6}$ and is the most common cause of legal blindness in industrialised countries. ${ }^{7}$ It represents a chronic disease with progressive stages and variable rates of progression over time. Clinically and histologically, AMD is generally classified into two major subtypes: dry or non-exudative AMD, of which geographic atrophy is a severe form, and wet or exudative AMD. Dry AMD progresses more slowly and manifests RPE and photoreceptor dysfunction and degeneration. ${ }^{8}$ Wet $\mathrm{AMD}$, on the other hand, is more debilitating and often develops after early dry AMD. The key feature of wet $\mathrm{AMD}$ is choroidal neovascularisation (CNV), the growth of new blood vessels from the choroids into the region underlying the RPE or extending into the subretinal space. $^{9}$ The holy grail of therapy for AMD is to avoid the development of $\mathrm{CNV}$. Despite a recent breakthrough with 


\section{BMJ Case Reports}
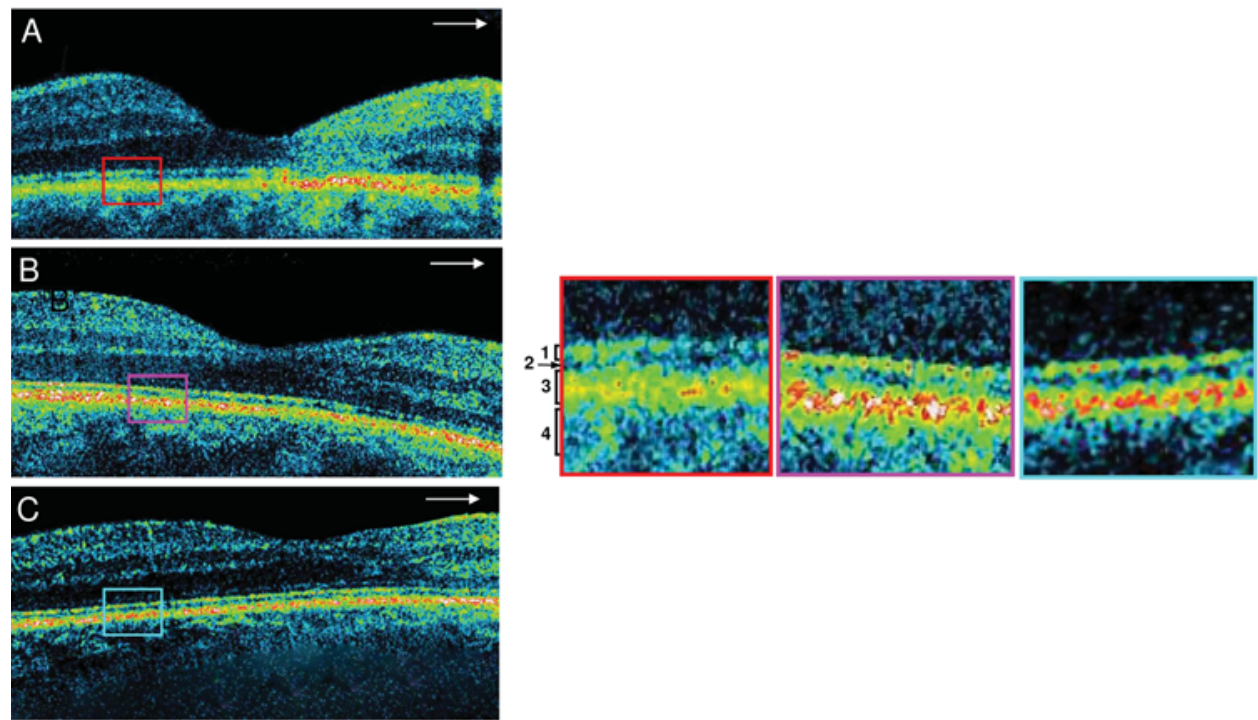

Figure 1 Optical coherence tomogram before treatment showing interface of the inner and outer segment of the photoreceptor layer. $\mathrm{RPE} /$ Bruch's membrane complex was disturbed with absence in many sites $(\mathrm{A})$. The eye 7 days after receiving intravitreal injection of dobesilate, with marked resolution of outer retinal layers (B). Aspect of the eye after 14 days of intravitreal dobesilate treatment (C). Right panels represent magnification of insets from A, B and C, respectively, each one framed in a different colour. (1) Interface of the inner and outer segment of the photoreceptor layer. (2) Outer segment-retinal pigment epithelium interdigitation. (3) Retinal pigment epithelium/ Bruch's membrane complex. (4) Choriocapillaries and choroidea.
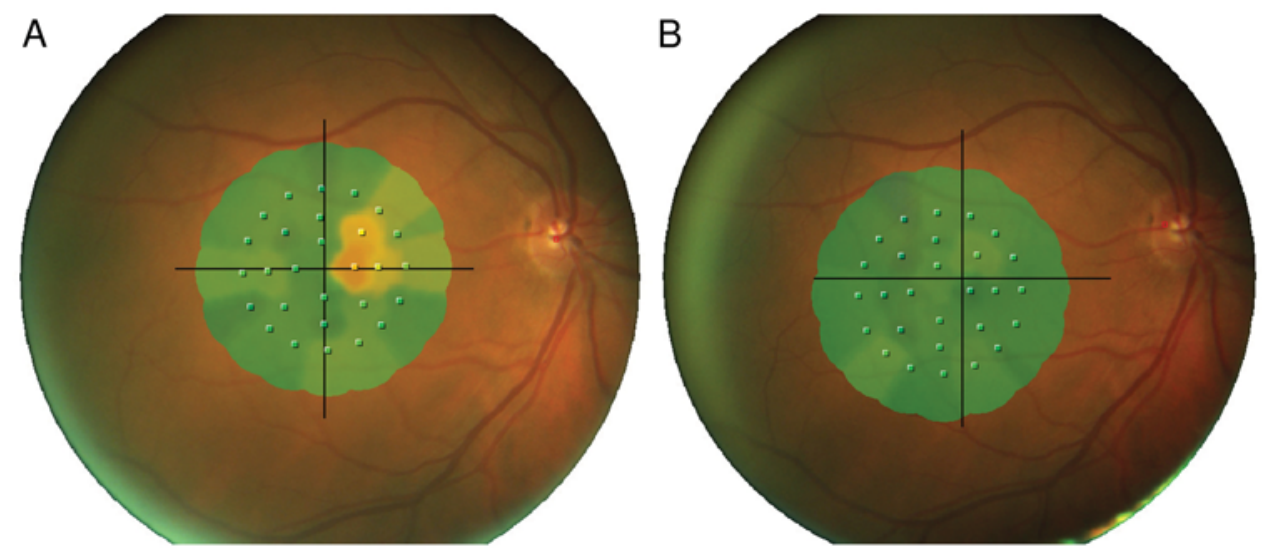

Attenuation scale $(\mathrm{dB})$ :

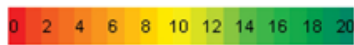

Figure 2 Fundus-monitored microperimetry map before (A) and after 14 days (B) of intravitreal dobesilate treatment.

antivascular endothelial growth factor therapy for neovascular AMD, so far, there are no treatments available for patients with dry AMD. To identify potential targets for intervention, a better understanding of the pathogenesis of dry AMD appears mandatory. Although the aetiology of $\mathrm{AMD}$ is not completely understood, it is indisputable that inflammation has a critical role in both dry and wet AMD. ${ }^{8}$ ${ }^{10-14}$ Consequently, conventional therapies based on inhibiting angiogenesis do not seem an appropriate strategy in the case of dry AMD. However, the aetiology of the disease suggests that the treatment of inflammation could be a suitable alternative to treat dry AMD.

The subretinal space, the interface between the apical surface of the RPE and the outer segments of photoreceptors, is a locus of particular interest in the relationship between inflammation and AMD. Microglial cell activation in the outer retina has been proposed as part of the pathogenic mechanism in some retinal diseases including AMD with its implication of photoreceptor and RPE loss. ${ }^{13} 15$ ${ }^{16}$ Microglial cells are the resident macrophages of the central nervous system that synthesise fibroblast growth factor (FGF) when they become activated. Since they also express FGF receptors, these growth factors should autocrinely contribute to sustain a chronic inflammation. ${ }^{17-19}$ In healthy retina, microglial cells are located in inactivated conditions mainly in the inner retina. Under normal conditions, the subretinal space is a zone of special immune privilege ${ }^{20}$ maintained by the activity of RPE cells which secrete immunosuppressive factors into this space, ${ }^{21}$ and also by the notable absence of retinal microglia in the outer retina. ${ }^{22}$ However, under conditions of advanced age and photoreceptor injury, retinal microglia cells translocate 

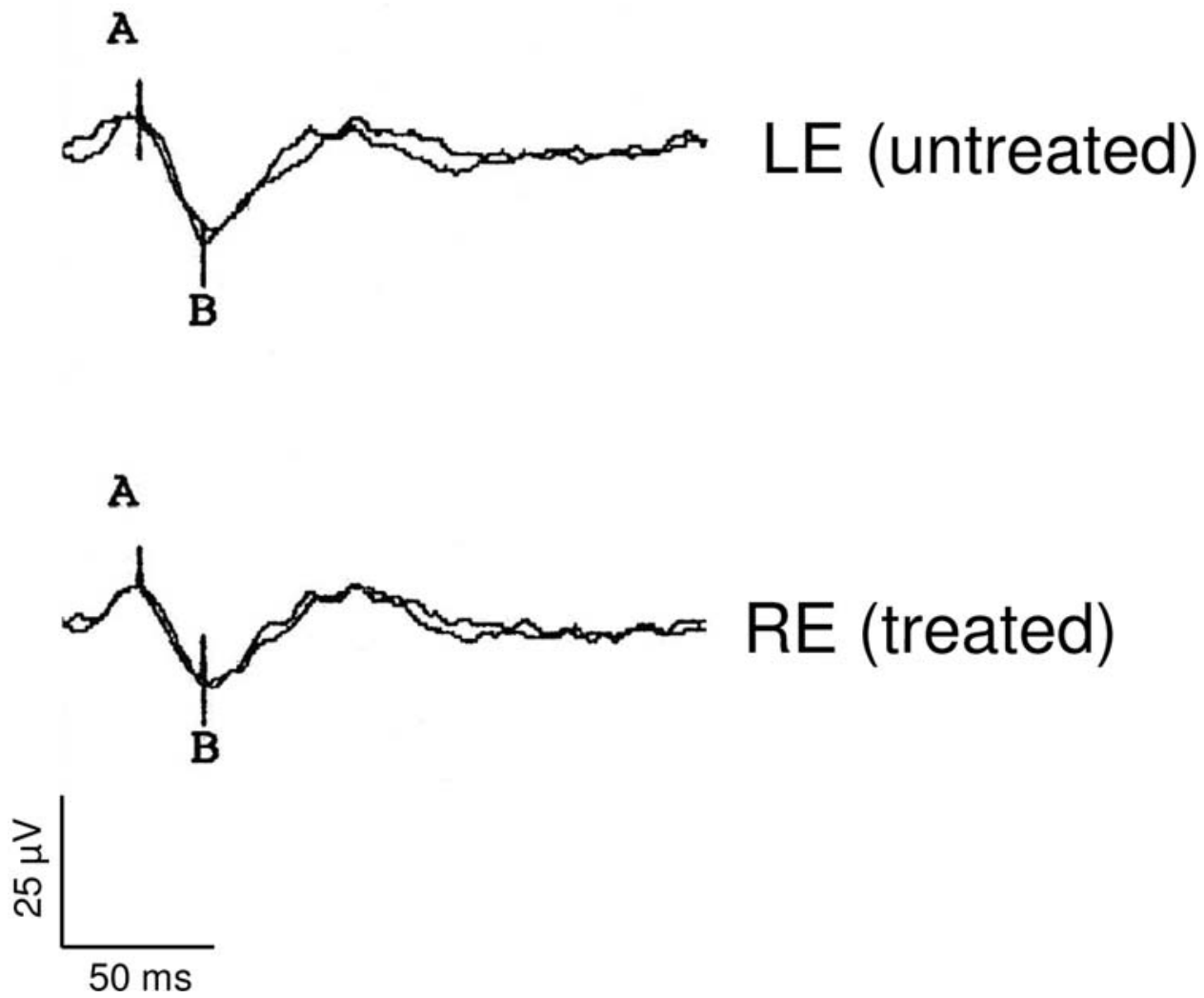

Figure 3 ERG traces corresponding to untreated and treated eyes, respectively, 1 month after intravitreal dobesilate injection. Traces corresponding to two subsequent measurements are superimposed in each case as estimation of its reproducibility.

from the inner retina into the outer retina and accumulate in the subretinal space, where they acquire the morphological features of activation. ${ }^{23} 24$ Importantly, activated microglia is found in the subretinal space of patients with AMD. $^{25}$

FGF, in spite of being an angiogenesis promoter, ${ }^{26}$ is involved also in inflammation ${ }^{27-30}$ and seems to play key roles in neurodegenerative diseases such as Alzheimer's and Parkinson's diseases as well as in AMD, through activation of microglial cells. ${ }^{19}$ The aim of the present interventional case was to find out whether intravitreal dobesilate, a FGF inhibitor, ${ }^{5}$ could constitute a therapeutic option in the treatment of dry AMD. The case here presented suggests that, indeed, dobesilate could be an efficient drug for early treatment of dry AMD. Although the implication of FGF in microglial cell migration from the inner retina to the outer retina, and its activation in this site in AMD has not been specifically studied, the general antimigratory ${ }^{5}$ and anti-inflammatory activities ${ }^{31-33}$ of dobesilate could explain its efficacy in dry AMD.

Calcium dobesilte is the active principle of Doxium, a drug used for more than 35 years that has been orally administered for the treatment of diabetic retinopathy with a good safety profile. ${ }^{34}$ Haritoglu et a ${ }^{\beta 5}$ have carried out a well-statistically performed study to assess the real clinical benefits of oral calcium dobesilate (Doxium) in the treatment of diabetic retinopathies. The study concluded that the oral administration of dobesilate did not show statistically significant clinical benefits. The discrepancy between these last results and those reported here may be explained on the basis of the administration procedures.
Probably the oral administration is not the best choice for dobesilate to reach the adequate concentration at the retina. Dobesilate has a very low product of solubility at the acidic $\mathrm{pH}$ of the stomach, and, further, readily oxidises at the duodenal pH. Accordingly, a local delivery seems a better choice in order to reach appropriate therapeutic concentrations of dobesilate in the case of well-delimited targets, as is the case reported here. The similarity of the ERG patterns of the treated and untreated eye (figure 3) shows that the intravitreal dobesilate administration does not seem to cause any obvious alterations of the retinal cells, since any damage of the photoreceptors that destroys the cells or reduces its responsiveness will lead to decrease in the ERG response amplitude.

Intravitreal dobesilate treatment led to normalisation of retinal structure and significant gain in visual acuity and may improve the future management of dry AMD. Obviously, the actual clinical value of dobesilate in dry $\mathrm{AMD}$ described here needs to be further investigated in a prospective randomised clinical trial with a longer follow-up. This study is ongoing.

\section{Learning points}

- Dry age-related macular degeneration is a retinal inflammatory disease associated with vision loss.

- There are no treatments available for this condition.

- Intravitreal dobesilate normalises retinal structure and function, paralleled with vision improvement. 
Competing interests None.

Patient consent Obtained.

\section{REFERENCES}

1. Green WR. Histopathology of age-related macular degeneration. Mol Vis 1999:5:27.

2. Fleckenstein M, Charbel Issa P, Helb HM, et al. High-resolution spectral domain-OCT imaging in geographic atrophy associated with age-related macular degeneration. Invest Ophthalmol Vis Sci 2008;49:4137-44.

3. Brar M, Kozak I, Cheng L, et al. Correlation between spectral-domain optical coherence tomography and fundus autofluorescence at the margins of geographic atrophy. Am J Ophthalmol 2009;148:439-44.

4. Aiello LP, Brucker AJ, Chang S, et al. Evolving guidelines for intravitreous injections. Retina (Philadelphia, Pa) 2004;24(5 Suppl):S3-19.

5. Fernández IS, Cuevas P, Angulo J, et al. Gentisic acid, a compound associated with plant defense and a metabolite of aspirin, heads a new class of in vivo fibroblast growth factor inhibitors. J Biol Chem 2010;285:11714-29.

6. Gehrs KM, Anderson DH, Johnson LV, et al. Age-related macular degeneration-emerging pathogenetic and therapeutic concepts. Ann Med 2006;38:450-71.

7. Fine SL, Berger JW, Maguire MG, et al. Age-related macular degeneration. N Engl J Med 2000;342:483-92.

8. Rodrigues EB. Inflammation in dry age-related macular degeneration. Ophthalmologica 2007;221:143-52.

9. Chappelow AV, Kaiser PK. Neovascular age-related macular degeneration: potential therapies. Drugs 2008;68:1029-36.

10. Nowak JZ. Age-related macular degeneration (AMD): pathogenesis and therapy. Pharmacol Rep 2006;58:353-63.

11. Patel $\mathbf{M}$, Chan CC. Immunopathological aspects of age-related macular degeneration. Semin Immunopathol 2008;30:97-110.

12. Hollyfield JG, Bonilha VL, Rayborn ME, et al. Oxidative damage-induced inflammation initiates age-related macular degeneration. Nat Med 2008;14:194-8.

13. Buschini E, Piras A, Nuzzi R, et al. Age related macular degeneration and drusen: neuroinflammation in the retina. Prog Neurobiol 2011;95:14-25.

14. Telander DG. Inflammation and age-related macular degeneration (AMD) Semin Ophthalmol 2011;26:192-7.

15. Wang J, Ohno-Matsui K, Yoshida T, et al. Amyloid-beta up-regulates complement factor B in retinal pigment epithelial cells through cytokines released from recruited macrophages/microglia: Another mechanism of complement activation in age-related macular degeneration. J Cell Physiol 2009;220:119-28.

16. Ma W, Zhao L, Wong WT. Microglia in the outer retina and their relevance to pathogenesis of age-related macular degeneration. Adv Exp Med Biol 2012; 723:37-42

17. Araujo DM, Cotman CW. Basic FGF in astroglial, microglial, and neuronal cultures: characterization of binding sites and modulation of release by lymphokines and trophic factors. J Neurosci 1992;12:1668-78.

18. Liu X, Mashour GA, Webster HF, et al. Basic FGF and FGF receptor 1 are expressed in microglia during experimental autoimmune encephalomyelitis: temporally distinct expression of midkine and pleiotrophin. Glia 1998;24:390-7.
19. Lee M, Kang Y, Suk K, et al. Acidic fibroblast growth factor (FGF) potentiates glial-mediated neurotoxicity by activating FGFR2 IIlb protein. J Biol Chem 2011;286:41230-45.

20. Streilein JW, Ma N, Wenkel H, et al. Immunobiology and privilege of neuronal retina and pigment epithelium transplants. Vision Res 2002;42:487-95.

21. Zamiri P, Sugita S, Streilein JW. Immunosuppressive properties of the pigmented epithelial cells and the subretinal space. Chem Immunol Allergy 2007; 92:86-93.

22. Lee JE, Liang $\mathrm{KJ}$, Fariss RN, et al. Ex vivo dynamic imaging of retinal microglia using time-lapse confocal microscopy. Invest Ophthalmol Vis Sci 2008;49:4169-76.

23. $\mathbf{N g ~ T F}$, Streilein JW. Light-induced migration of retinal microglia into the subretinal space. Invest Ophthalmol Vis Sci 2001:42:3301-10.

24. $\mathbf{X u} \mathbf{H}$, Chen M, Manivannan A, et al. Age-dependent accumulation of lipofuscin in perivascular and subretinal microglia in experimental mice. Aging Cell 2008;7:58-68

25. Gupta N, Brown KE, Milam AH. Activated microglia in human retinitis pigmentosa, late-onset retinal degeneration, and age-related macular degeneration. Exp Eye Res 2003;76:463-71.

26. Giménez-Gallego G, Rodkey J, Bennett C, et al. Brain-derived acidic fibroblast growth factor: complete amino acid sequence and homologies. Science 1985;230:1385-8.

27. Byrd VM, Ballard DW, Miller GG, et al. Fibroblast growth factor-1 (FGF-1) enhances IL-2 production and nuclear translocation of NF-kappaB in FGF receptor-bearing Jurkat T cells. J Immunol 1999;162:5853-9.

28. Meij JT, Sheikh F, Jimenez SK, et al. Exacerbation of myocardial injury in transgenic mice overexpressing FGF-2 is T cell dependent. Am J Physiol Heart Circ Physiol 2002;282:H547-55.

29. Rossini M, Cheunsuchon B, Donnert E, et al. Immunolocalization of fibroblast growth factor-1 (FGF-1), its receptor (FGFR-1), and fibroblast-specific protein-1 (FSP-1) in inflammatory renal disease. Kidney Int 2005;68:2621-8.

30. Zittermann SI, Issekutz AC. Basic fibroblast growth factor (bFGF, FGF-2) potentiates leukocyte recruitment to inflammation by enhancing endothelial adhesion molecule expression. Am J Pathol 2006;168:835-46.

31. Bussolino F, Biffignandi P, Arese P. Platelet-activating factor-a powerful lipid autacoid possibly involved in microangiopathy. Acta Haematol 1986:75:129-40.

32. Piller NB. Assessment of the anti-inflammatory action of calcium dobesilate. Effect on macrophages attaching to subcutaneously implanted coverslips in guinea pigs. Arzneimittelforschung 1990;40:698-700.

33. Wollina U, Abdel-Naser MB, Mani R. A review of the microcirculation in skin in patients with chronic venous insufficiency: the problem and the evidence available for therapeutic options. Int J Low Extrem Wounds 2006;5:169-80.

34. Allain $\mathbf{H}$, Ramelet AA, Polard E, et al. Safety of calcium dobesilate in chronic venous disease, diabetic retinopathy and haemorrhoids. Drug Saf 2004;27:649-60.

35. Haritoglou C, Gerss J Sauerland C et al: CALDIRET study group. Effect of calcium dobesilate on occurrence of diabetic macular oedema (CALDIRET study): randomised, double-blind, placebo-controlled, multicentre trial. Lancet 2009:373:1364-71

This pdf has been created automatically from the final edited text and images.

Copyright 2012 BMJ Publishing Group. All rights reserved. For permission to reuse any of this content visit http://group.bmj.com/group/rights-licensing/permissions.

BMJ Case Report Fellows may re-use this article for personal use and teaching without any further permission.

Please cite this article as follows (you will need to access the article online to obtain the date of publication).

Cuevas $P$, Outeiriño L A, Angulo J, Giménez-Gallego G. Treatment of dry age-related macular degeneration with dobesilate. BMJ Case Reports 2012;10.1136/bcr.02.2012.5942, Published XXX

Become a Fellow of BMJ Case Reports today and you can:

- Submit as many cases as you like

- Enjoy fast sympathetic peer review and rapid publication of accepted articles

- Access all the published articles

- Re-use any of the published material for personal use and teaching without further permission

For information on Institutional Fellowships contact consortiasales@bmjgroup.com

Visit casereports.bmj.com for more articles like this and to become a Fellow

Keep up to date with all published cases by signing up for an alert (all we need is your email address) http://casereports.bmj.com/cgi/alerts/etoc 